\title{
Radiographic and Clinical Outcomes Following Pedicle Subtraction Osteotomy : Minimum 2-Year Follow-Up Data
}

\author{
Ho Yong Choi, ${ }^{1}$ Seung-Jae Hyun, ${ }^{2}$ Ki-Jeong Kim, ${ }^{2}$ Tae-Ahn Jahng, ${ }^{2}$ Hyun-Jib Kim ${ }^{2}$ \\ Department of Neurosurgery, Kyung Hee University Hospital at Gangdong, Kyung Hee University School of Medicine, Seoul, Korea \\ Department of Neurosurgery, ${ }^{2}$ Spine Center, Seoul National University Bundang Hospital, Seoul National University College of Medicine, \\ Seongnam, Korea
}

Objective : The purpose of this study was to report the results of pedicle subtraction osteotomy (PSO) for fixed sagittal imbalance with a minimum 2-year follow-up. Besides, authors evaluated the effect of adjunctive multi-level posterior column osteotomy (PCO) on achievement of additional lumbar lordosis (LL) during PSO.

Methods : A total of 31 consecutive patients undergoing PSO for fixed sagittal imbalance were enrolled and analyzed. Correction angle of osteotomized vertebra (PSO angle) and other radiographic parameters including pelvic incidence (PI), thoracic kyphosis, LL, and sagittal vertical axis (SVA) were evaluated. Clinical outcomes and surgical complications were also assessed.

Results : The mean age was $66.0 \pm 9.3$ years with a mean follow-up period of $33.2 \pm 10.5$ months. The mean number of fused segments was 9.6 \pm 3.5 . The mean operative time and surgical bleeding were $475.9 \pm 160.5$ minutes and $1406.1 \pm 932.1 \mathrm{~mL}$, respectively. The preoperative SRS-22 score was $2.3 \pm 0.7$ and improved to $3.2 \pm 0.8$ at the final follow-up. The mean PI was $54.5 \pm 9.5^{\circ}$. LL was changed from $7.0 \pm 28.9^{\circ}$ to $-50.2 \pm 13.2^{\circ}$. The PSO angle was $33.7 \pm 13.5^{\circ}\left(15.6 \pm 20.1^{\circ}\right.$ preoperatively, $-16.1 \pm 19.4^{\circ}$ postoperatively). The difference of correction angle of $\mathrm{LL}\left(57.3^{\circ}\right)$ was greater about $23.6^{\circ}$ than which of PSO angle $\left(33.7^{\circ}\right)$. SVA was improved from $189.5 \pm 93.0 \mathrm{~mm}$, preoperatively to $12.4 \pm 40.8 \mathrm{~mm}$, postoperatively. There occurred six, eight, and 14 cases of complications at intraoperative, early ( $<2$ weeks) postoperative, and late ( $\geq 2$ weeks) postoperative period, respectively. Additional operations were needed in nine patients due to the complications.

Conclusion : PSO could provide satisfactory results for patients with fixed sagittal imbalance regarding clinical and radiographic outcomes. Additional correction of LL could be achieved with conduction of adjunctive multi-level PCOs during PSO.

Key Words : Osteotomy · Spinal curvatures · Follow-up studies $\cdot$ Kyphosis $\cdot$ Spinal fusion.

\section{INTRODUCTION}

Patients with fixed sagittal malalignment are unable to stand erect without flexing their hips or knees due to the loss of segmental lumbar lordosis (LL) ${ }^{5,26,27)}$. Disruption of normal sagittal alignment results in significant pain and disability, and associated with low health-related quality of life ${ }^{13)}$. For patients with fixed sagittal imbalance who failed to conservative

- Received : August 23, 2018 •Revised : November 10, 2018 •Accepted : January 26, 2019

- Address for reprints : Seung-Jae Hyun

Department of Neurosurgery, Spine Center, Seoul National University Bundang Hospital, Seoul National University College of Medicine, 82 Gumi-ro, 173beon-gil, Seongnam 13620 , Korea

Tel : +82-31-787-7164, Fax : +82-31-787-4059, E-mail : hyunsj@snu.ac.kr, ORCID : https://orcid.org/0000-0003-2937-5300

This is an Open Access article distributed under the terms of the Creative Commons Attribution Non-Commercial License (http://creativecommons.org/licenses/by-nc/4.0) which permits unrestricted non-commercial use, distribution, and reproduction in any medium, provided the original work is properly cited. 
management, extensive spinal fusion with osteotomy is usually required ${ }^{3,20,29)}$. Among those osteotomies, pedicle subtraction osteotomy (PSO) is the most widely performed one, especially in severe fixed sagittal imbalance ${ }^{4,9,12)}$.

According to the increasing incidence of adult spinal deformity with aging population as well as the understanding of the importance of sagittal alignment of the spine, the use of PSO has markedly expanded ${ }^{25)}$. Gum et al. ${ }^{14)}$ reported the utilization of PSO procedure was increased by 3.2-fold within four years in the United States. In spite of the wide acceptance, the complication rate of PSO appears still higher than other spinal procedure ${ }^{10,17,18,31)}$.

The purpose of this study was to report the results of PSO for fixed sagittal imbalance with minimum 2-year follow-up. Besides, authors evaluated the effect of adjunctive multi-level PCO on achievement of additional LL during PSO.

\section{MATERIALS AND METHODS}

\section{Demographic of patients}

We obtained informed consent from all the patients and also approval from the Institutional Review Board of Seoul National University Bundang Hospital (approval No. B-1603/338-109). Consecutive adult patients ( $>18$ year-old) who underwent PSO for fixed sagittal imbalance were sorted and analyzed from a single institutional database. All patients were operated by a single surgeon and observed for more than 2-year. Among total of 36 consecutive patients, five patients were excluded from this study because of the loss of follow-up or short of follow-up period (12.0-19.9 months of follow-up). Finally, 31 patients who underwent PSO between February 2012 and March 2016 were enrolled in this study. All patients suffered from persistent severe pain (visual analogue scale [VAS] $\geq 6$ ), neurological deficit, or progressive deformity in spite of sufficient conservative treatment. Conservative treatment was comprised of physical therapy, medication, back muscle exercise, brace, and epidural steroid injection for more than three months. Decision for performing PSO was made for patients with type 2 sagittal imbalance (global sagittal imbalance) and lumbar curve without motion segment because of ankylosing spondylitis, severe degenerative change, or previous circumferential fusion along multiple vertebrae.

\section{Radiographic assessment}

Long-cassette $(14 \times 36$ inch) anteroposterior and lateral standing plain radiographs obtained before surgery, immediately following surgery, and at the most recent follow-up were analyzed retrospectively. Sagittal vertical axis (SVA) was determined as the distance from the $\mathrm{C} 7$ sagittal plumb line to the perpendicular line drawn from the superior posterior corner of the S1 vertebral body. The thoracic kyphosis (TK) was measured between the lower endplates of T5 and T12. LL was measured between the upper endplate of L1 and S1. The angle at the PSO site was defined between the upper endplate of the adjacent upper vertebra and the lower endplate of the adjacent lower vertebra. Proximal junctional kyphosis (PJK) was defined as a proximal junctional angle of $10^{\circ}$ greater than the preoperative value.

\section{Clinical assessment}

Clinical data including sex, age, and primary or revision surgery status were collected by medical chart review, retrospectively. Operative details such as the level of osteotomy, number of fused segment, operation time, estimated blood loss (EBL), transfused volume of red blood cell (RBC), and length of hospital stay were obtained. Complications were evaluated and divided into three groups regarding time of onset; intraoperative, early-postoperative ( $<2$ weeks), and late-onset ( $\geq 2$ weeks). Clinical outcomes were assessed by Scoliosis Research Society-22 (SRS-22) questionnaire, prior to operation and at the ultimate follow-up (at least 2-year after operation). Patient questionnaire was filled out by every patient themselves. Then, physical assistant registered the data into the database immediately after the completion of the survey.

\section{Surgical procedure}

The patients were positioned prone on the radiolucent operative table with chest bolster and pelvic girdles (Jackson table), to achieve maximal lordotic curvature and to avoid abdominal pressure. Intraoperative neurophysiological monitoring using somatosensory and motor evoked potentials was applied to every patient. Intraoperative administration of tranexamic acid and installation of cell salvage system were done in order to reduce surgical bleeding and RBC transfusion. Subperiosteal dissection was performed to expose bony structure as far as the tip of transverse process. Placement of pedicle screws with or without pelvic screws (S2 alar-iliac screws) was performed using freehand technique ${ }^{8}$. Multi-level posterior col- 
umn osteotomies (PCO) as a Ponte procedure were performed at every lumbar vertebra.

Removal of all posterior elements is conducted at the PSO segment including the spinous process, lamina, and the superior and inferior articular processes adjacent to the pedicle. In addition, cephalad and caudal laminae were undercut to avoid dural buckling or neural impingement during closure of posterior column. Following cutting of proximal junction of transverse processes bilaterally, lateral surface of the vertebral body was carefully dissected while protecting segmental vessels. Next, pediculectomy and wedge-shaped cancellous bone removal were done. Usually, a temporary rod was placed across the osteotomy site to prevent subluxation or premature closure. Lateral cortex was removed with wedge-shaped, and remnant posterior cortex was depressed and fractured with downward cutting curette. Consequently, pedicle subtraction was accomplished with downward force by an operator and secured with multiple rod construct. After completing the fixation procedure, autografts and allografts were placed over the laminae, facet joints and transverse processes.

\section{Statistical analysis}

Statistical analysis was performed using IBM SPSS version 22.0 software for Windows (IBM, Corp., Armonk, NY, USA). The distributions of the variables were demonstrated as the mean value and standard deviation. Paired t-test was used to analyze the paired variables before and after osteotomy. Statistical significance was set at $p<0.05$.

Table 1. Demographic data

\begin{tabular}{lc}
\hline Variable & Value \\
\hline Age (years) & $66.0 \pm 9.3$ \\
Male : female & $4: 27$ \\
Etiology of deformity & \\
Degenerative lumbar flatback & 16 \\
Postoperative flatback & 11 \\
Posttraumatic kyphosis & 2 \\
Tuberculous kyphosis & 2 \\
Prior operation & $1.2 \pm 1.2$ \\
Number of times & $20 / 31(64.5 \%)$ \\
Number of patients
\end{tabular}

\section{RESULTS}

\section{Patients demographics}

The patients included in this study were 27 females and four males, with a mean age of 66.0 19.3 years (Table 1). A mean follow-up period was $33.2 \pm 10.5$ months. In terms of diagnosis, there were 16 cases of degenerative lumbar flatback, 11 cases of postoperative flatback, two cases of posttraumatic kyphosis, and two cases of tuberculous kyphosis. 64.5\% (20/31) of patients had prior spinal surgeries, with a mean number of 1.2 \pm 1.2 .

\section{Operative and clinical outcomes}

Operative details are summarized in Table 2. The most common level of osteotomy was L3 (15 cases), followed by L4 (eight cases), L1 (four cases), L2 (two cases), and T12 (two cases). The mean number of fused segments was 9.6 \pm 3.5 . Pelvic fixation, by means of S2 alar-iliac screws, was conducted in 27 patients, and 19 patients received anterior column support by transforaminal lumbar interbody fusion at least one level. The mean operative time was $475.9 \pm 160.5$ minutes. The amount of surgical bleeding was $1406.1 \pm 932.1 \mathrm{~mL}$, and the volume of transfused $\mathrm{RBC}$ was

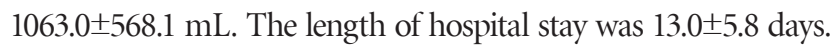
The preoperative SRS-22 score was $2.3 \pm 0.7$, which improved to

Table 2. Operative characteristics

\begin{tabular}{lc}
\hline Variable & Value \\
\hline Number of fused segment & $9.6 \pm 3.5$ \\
Surgical time (minutes) & $475.9 \pm 160.5$ \\
Estimated blood loss $(\mathrm{mL})$ & $1406.1 \pm 932.1$ \\
Volume of transfused RBC $(\mathrm{mL})$ & $1063.0 \pm 568.1$ \\
Length of hospital stay (days) & $13.0 \pm 5.8$ \\
\hline
\end{tabular}

Values are presented as mean \pm standard deviation. RBC : red blood cell

Table 3. Clinical outcomes

\begin{tabular}{lccc}
\hline Variable & Preoperative & Final & $p$-value \\
\hline SRS-22 & $2.3 \pm 0.7$ & $3.2 \pm 0.8$ & 0.000 \\
Function & $2.4 \pm 0.9$ & $2.9 \pm 0.9$ & 0.019 \\
Pain & $2.5 \pm 0.9$ & $3.3 \pm 1.0$ & 0.001 \\
Self-image & $1.9 \pm 0.6$ & $3.2 \pm 0.9$ & 0.000 \\
Mental health & $2.6 \pm 0.9$ & $3.2 \pm 0.9$ & 0.022 \\
Satisfaction with & & $3.7 \pm 0.9$ & \\
management & & & \\
\hline
\end{tabular}

SRS-22 : Scoliosis Research Society-22 score 
$3.2 \pm 0.8$ at the final follow-up $(p=0.000)$. All subscales in SRS-22 were significantly improved at the final follow-up, compared to those of preoperative value. The score of satisfaction with management was $3.7 \pm 0.9$ (Table 3).

\section{Radiographic outcomes}

The mean pelvic incidence was $54.5 \pm 9.5^{\circ}$ (Table 4). TK preoperatively and postoperatively was $16.2 \pm 18.5^{\circ}$ and $27.0 \pm 12.8^{\circ}$, respectively. LL was changed from $7.0 \pm 28.9^{\circ}$ to $-50.2 \pm 13.2^{\circ}$. The correction angle of LL was $57.3 \pm 25.6^{\circ}$ and sustained until last follow-up (loss of correction of $2.9 \pm 6.1^{\circ}$ ). The osteotomized vertebral angle was changed from $15.6 \pm 20.1^{\circ}$ preoperatively to $-16.1 \pm 19.4^{\circ}$ postoperatively. The angle of correction in osteoto-

Table 4. Radiographic data

\begin{tabular}{|c|c|}
\hline Variable & Value \\
\hline Pelvic incidence $\left({ }^{\circ}\right)$ & $54.5 \pm 9.5$ \\
\hline \multicolumn{2}{|l|}{ Thoracic kyphosis $\left({ }^{\circ}\right)$} \\
\hline Preoperative & $16.2 \pm 18.5$ \\
\hline Postoperative & $27.0 \pm 12.8$ \\
\hline Ultimate follow-up & $33.6 \pm 15.2$ \\
\hline Correction angle & $10.8 \pm 11.9$ \\
\hline Loss of correction angle & $7.1 \pm 10.1$ \\
\hline \multicolumn{2}{|l|}{ Lumbar lordosis $\left(^{\circ}\right)$} \\
\hline Preoperative & $7.0 \pm 28.9$ \\
\hline Postoperative & $-50.2 \pm 13.2$ \\
\hline Ultimate follow-up & $-46.7 \pm 13.1$ \\
\hline Correction angle & $-57.3 \pm 25.6$ \\
\hline Loss of correction angle & $2.9 \pm 6.1$ \\
\hline \multicolumn{2}{|l|}{ Sagittal vertical axis (mm) } \\
\hline Preoperative & $189.5 \pm 93.0$ \\
\hline Postoperative & $12.4 \pm 40.8$ \\
\hline Ultimate follow-up & $44.8 \pm 48.2$ \\
\hline Correction length & $-177.1 \pm 83.0$ \\
\hline Loss of correction length & $32.8 \pm 40.7$ \\
\hline \multicolumn{2}{|l|}{ Angle at the PSO site $\left(^{\circ}\right)$} \\
\hline Preoperative & $15.6 \pm 20.1$ \\
\hline Postoperative & $-18.0 \pm 17.8$ \\
\hline Ultimate follow-up & $-16.1 \pm 19.4$ \\
\hline Correction angle & $-33.7 \pm 13.5$ \\
\hline Loss of correction angle & $1.9 \pm 10.8$ \\
\hline
\end{tabular}

Values are presented as mean \pm standard deviation. PSO : pedicle subtraction osteotomy mized vertebra (PSO angle) was $33.7 \pm 13.5^{\circ}$. The difference of correction angle between LL and PSO segment was $23.6^{\circ}$. The preoperative SVA was $189.5 \pm 93.0 \mathrm{~mm}$, where the postoperative value was decreased to $12.4 \pm 40.8 \mathrm{~mm}$. The loss of correction of SVA was $32.8 \pm 40.7 \mathrm{~mm}$ (last SVA of $44.8 \pm 48.2 \mathrm{~mm}$ ).

\section{Complications}

Twenty out of 31 patients suffered from 28 complications (Table 5). Thus, the rate of total complications was $90.3 \%$ (28/31). Six cases of complications were occurred intraoperatively. Dural tear was most common (four cases), followed by screw malposition and chin sore (one case each).

There were eight complications during early postoperative period ( $<2$ weeks). There were two cases of postoperative motor deficit, which required revision surgery in one patient. One patient suffered from postoperative voiding difficulty which required continuous intermittent catheterization. One patient suffered from postoperative wound dehiscence, and underwent revision surgery with local flap. Other complications were urinary tract infection, hydronephrosis, atrial fibrillation, and pulmonary effusion.

Late postoperative period complications ( $\geq 2$ weeks) were

Table 5. Summary of complications

\begin{tabular}{|c|c|c|}
\hline Type & Number & $\begin{array}{l}\text { Additional } \\
\text { surgery }\end{array}$ \\
\hline \multicolumn{3}{|l|}{ Intraoperative } \\
\hline Dural tear & 4 & 1 \\
\hline Screw malposition & 1 & 1 \\
\hline Chin sore & 1 & \\
\hline \multicolumn{3}{|l|}{ Perioperative (<2 weeks) } \\
\hline Motor weakness & 2 & 1 \\
\hline Voiding difficulty & 1 & \\
\hline Wound dehiscence & 1 & 1 \\
\hline Urinary tract infection & 1 & \\
\hline Hydronephrosis & 1 & \\
\hline Atrial fibrillation & 1 & \\
\hline Pulmonary effusion & 1 & \\
\hline \multicolumn{3}{|l|}{ Late-onset ( $\geq 2$ weeks) } \\
\hline Proximal junctional failure & 8 & 1 \\
\hline Rod fracture & 4 & 4 \\
\hline Screw loosening & 2 & \\
\hline Total & 28 (in 20 patients) & 9 (in 9 patients) \\
\hline
\end{tabular}


identified in 14 cases. There were eight cases of PJK, one of which required revision surgery. There were four cases of rod fracture which required additional surgeries. Screw loosening was identified on routine follow-up in two patients with close observation. Additional operations were necessary in nine cases as a consequence of such complications.

\section{DISCUSSION}

In this study, we evaluated the radiographic and clinical outcomes following PSO, with a minimum 2-year follow-up.
PSO showed strong effect for correction of the segmental angle of osteotomized vertebra $\left(33.7 \pm 13.5^{\circ}\right)$. Regarding sagittal imbalance, this study revealed significant improvement of SVA following PSO (from 189.5 $\pm 93.0 \mathrm{~mm}$ preoperatively to $12.4 \pm 40.8 \mathrm{~mm}$ postoperatively). Radiographic outcomes including the PSO angle and improvement of sagittal malalignment were comparable to previous studies ${ }^{5,12,15,19)}$.

It is noteworthy that the correction of $\operatorname{LL}\left(57.3^{\circ}\right)$ is quite greater compared to earlier reports. According to the most literatures previously published, the correction amount of LL is approximately $30^{\circ}$, which is nearly similar with the PSO angle $^{5,15,19,24,28)}$. That reflects most amount of LL correction was
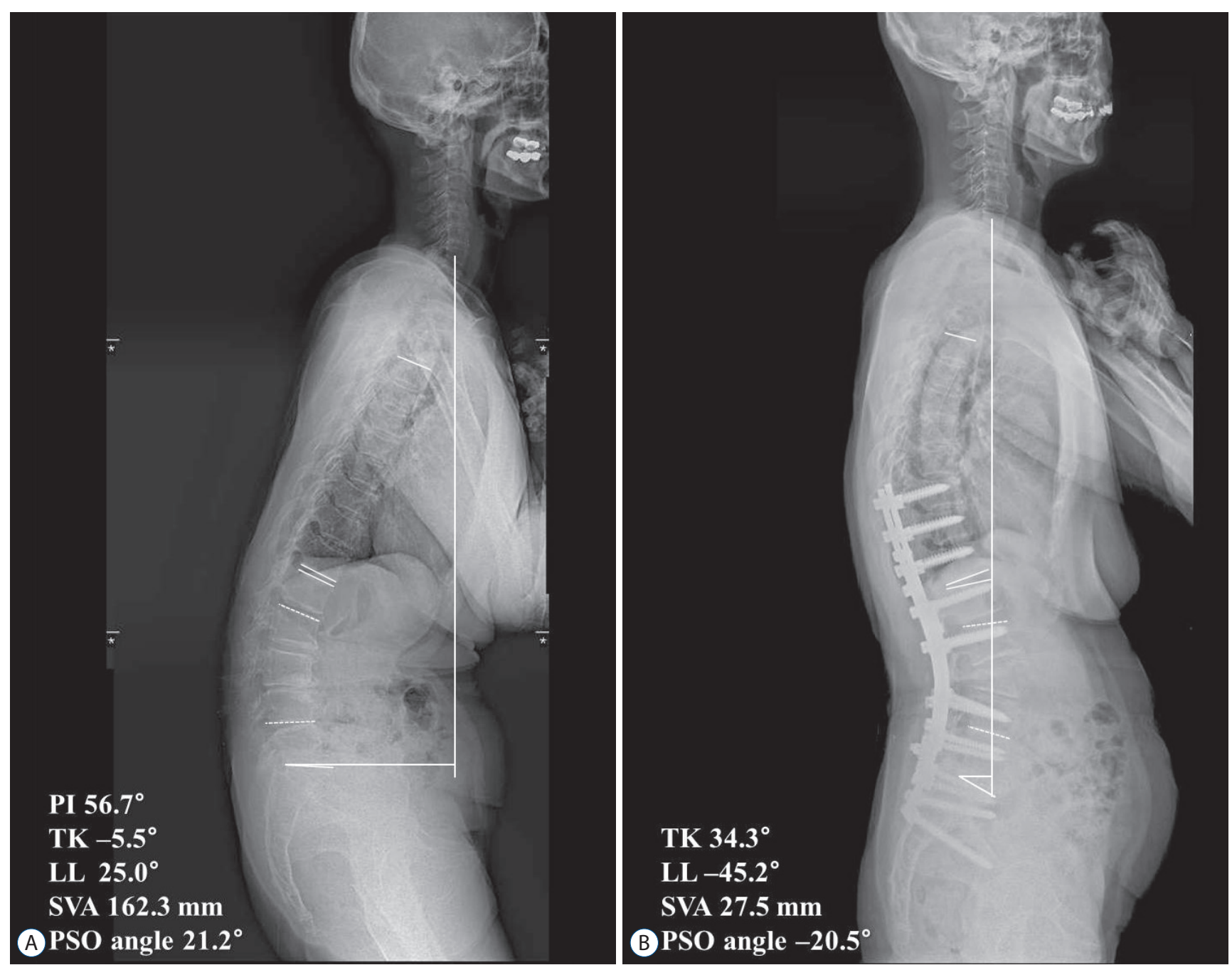

Fig. 1. A 77-year old female patient presenting with stooped posture and pain on her back and lower extremities. A : Preoperative sagittal whole spine X-ray showed sagittal imbalance with lumbar kyphosis. PSO with posterior instrumented fusion from T10 to pelvis was done. B: Sagittal balance was improved at final follow-up. Owing to multiple posterior column osteotomies in addition to PSO, the correction amount of lumbar lordosis $\left(70.2^{\circ}\right)$ is far greater than that of PSO angle $\left(41.7^{\circ}\right)$. PI : pelvic incidence, TK: thoracic kyphosis, LL : lumbar lordosis, SVA : sagittal vertical axis, PSO : pedicle subtraction osteotomy. 
achieved within the PSO segment. On the other hand, in one study, the correction amount of LL was only $13^{\circ}$, whereas PSO angle was $27.2^{\circ}$, which is on the contrary to the present study. Authors concluded that compensatory low-LL was reduced as a response of corrected local mid-LL following thoracic PSOs in some patients ${ }^{12}$.

In this study, authors corrected additional angle of $23.6^{\circ}$ regarding LL $\left(57.3^{\circ}\right)$ over the angle of correction at PSO segment $\left(33.7^{\circ}\right)$. Authors think that performance of multi-level PCO (Ponte procedure) at every lumbar vertebra was attributed to gain additional LL (Fig. 1). Recently, multi-level PCO was reported as effective as PSO per se, and regarded as a viable op- tion for the correction of rigid adult spinal deformity ${ }^{16)}$. We think performing additional multi-level PCO during PSO would be beneficial to achieve more suitable LL. Whereas, in some patients with already fused lumbar spine due to previous surgery, the role of additional PCO may be limited because the PCO is on the premise of existence of mobile segment (Fig. 2).

The perioperative data is mostly comparable to previous studies such as surgical time, number of fused segment, and length of hospital stay. In earlier study, Bridwell et al. ${ }^{5)}$ reported the mean surgical time of 730 minutes. Recent literatures reported generally more reduced surgical time (336-438 minutes $)^{10,12,15)}$, which is similar to our study (491 minutes). Re-
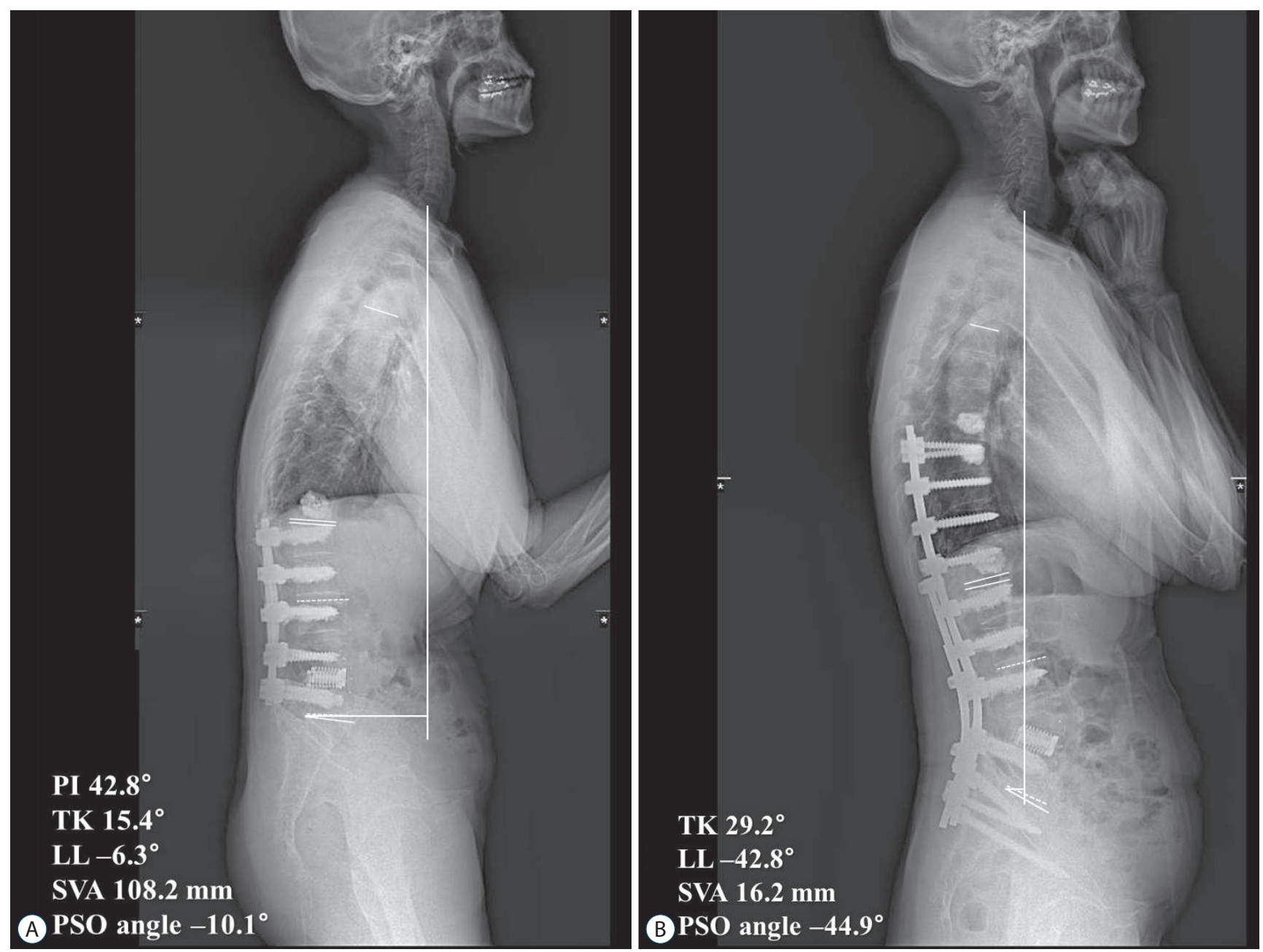

Fig. 2. A 71-year-old female patient presenting with stooped posture and pain on her back and lower extremities. She underwent prior lumbar spine surgeries at another hospital. A : Preoperative sagittal whole spine X-ray showed spinal instrumentation from L1 to L5 with bone cement materials at multiple levels. L4 PSO with posterior instrumented fusion from T9 to pelvis, and prophylactic vertebroplasties at T8 and T9 were done. B : Because of nearly fused posterior element of the lumbar spine, the correction amount of lumbar lordosis $\left(36.5^{\circ}\right)$ is almost same with PSO angle (34.8 $)$. PI : pelvic incidence, TK : thoracic kyphosis, LL : lumbar lordosis, SVA : sagittal vertical axis, PSO : pedicle subtraction osteotomy. 
garding EBL, present study showed noticeably less EBL (1428 $\mathrm{mL})$ compared to other studies $(2371-5800 \mathrm{~mL})^{5,10,12,15,33)}$. Possible explanation of reduced EBL in current study is various blood conservation strategies in our institution including prompt bleeding control of decorticated bone and epidural space, intraoperative tranexamic acid infusion, and packing of gauze soaked with hemostatic agent to exposed surgical field ${ }^{7}$.

The clinical outcome was favorable following PSO, which is concordant with the previous studies ${ }^{2,33}$. Although the assessment methods of clinical outcome were various among studies, most studies reported significant improvement of clinical outcome following PSO. It is noteworthy that the subscale of self-image was improved the most, whereas functional category the least, in the present study. These findings are also consistent with most previous literatures ${ }^{11,22,23)}$, possibly reflecting the double sidedness of the deformity correction surgery including long level instrumentation.

PSO is technically demanding procedure and associated with substantial rates of complications compared to other spinal procedures ${ }^{2,15,30)}$. In our study, the prevalence of intraoperative complications (19.4\%) and early post-operative complications (25.8\%) was comparable to previous studies ${ }^{1,19,23,24)}$. Daubs et al. ${ }^{10)}$ thoroughly evaluated perioperative (within 3 -month) complications of PSO in 65 patients, and demonstrated intraoperative complication rates of $23 \%$ and total postoperative complication rates of $52.3 \%$. They reported dural tear was the most common intraoperative complications (18.4\%), which was comparable to the current study (12.9\%).

One of the most serious complications during early postoperative period is neurological deteriorations following PSO. In the present study, postoperative neurological deficits were identified in three patients (two patients with transient motor weakness, one patient with permanent voiding difficulty) with the prevalence of $9.7 \%$ (3/31). Buchowski et al. ${ }^{6}$ reported the intraoperative and postoperative deficits were seen in $11.1 \%$ of patients who underwent PSO (12/108). More recently, Eskilsson et al. ${ }^{12)}$ and Daubs et al. ${ }^{10)}$ reported the prevalence of neurological complications was 11\% (12/104), and 6.2\% (4/65), respectively. Generally, the prevalence of neurological complication in the present study was similar to other studies ${ }^{23,24)}$.

Majority of late-onset complications are associated with junctional kyphosis (with or without junctional failure) and pseudarthrosis presenting with instrument failure or loss of sagittal balance. There were fourteen cases of late-onset com- plications, including eight cases of PJK (25.8\%). The rates of PJK reported quiet vary, however, most literatures report a rate of $20 \%$ to $40 \%^{17,21,24,32)}$. Although longer period of followup is needed, our results regarding PJK were comparable to previous reports. There were six patients suggesting pseudarthrosis (19.4\%), including four cases of rod fracture and two cases screw loosening. The rate of pseuarthrosis was comparable to the results by Yang et al. ${ }^{33}$, however, additional period of follow-up is necessary since the pseudarthrosis is known to occur even after 2 years postoperatively ${ }^{233}$.

This study was limited by the retrospective design with analysis of medical and radiographic records. Moreover, relatively small number of patients enrolled with short-term duration of follow-up may weaken the validity of this study. Despite those weaknesses, however, the radiographic outcomes and complication rates were mostly comparable to previous studies with relatively large sample size, which would assure the relevance of the present study. The unique point of the current study is the performance of adjunctive multi-level PCO in addition to PSO, which achieved greater correction angle of LL compared to the PSO angle.

\section{CONCLUSION}

PSO could provide satisfactory results for patients with fixed sagittal imbalance regarding clinical and radiographic outcomes. Complication rates were comparable to previous studies, however, longer period of follow-up would be needed to evaluate late-onset complications such as PJK and pseudarthrosis. Additional correction of LL could be achieved with conduction of adjunctive multi-level PCO during PSO.

\section{CONFLICTS OF INTEREST}

No potential conflict of interest relevant to this article was reported.

\section{INFORMED CONSENT}

Informed consent was obtained from all individual participants included in this study. 


\section{AUTHOR CONTRIBUTIONS}

\author{
Conceptualization : $\mathrm{SJH}$ \\ Data curation : HYC \\ Formal analysis : HYC \\ Methodology: SJH \\ Project administration : HYC \\ Visualization : HYC \\ Writing - original draft : HYC \\ Writing - review \& editing : SJH, KJK, TAJ, HJK
}

\section{References}

1. Alzakri A, Boissière L, Cawley DT, Bourghli A, Pointillart V, Gille O, et al. : L5 pedicle subtraction osteotomy: indication, surgical technique and specificities. Eur Spine J 27 : 644-651, 2018

2. Auerbach JD, Lenke LG, Bridwell KH, Sehn JK, Milby AH, Bumpass D, et al. : Major complications and comparison between 3-column osteotomy techniques in 105 consecutive spinal deformity procedures. Spine (Phila Pa 1976) 37 : 1198-1210, 2012

3. Bae J, Lee SH : Minimally invasive spinal surgery for adult spinal deformity. Neurospine 15 : 18-24, 2018

4. Bridwell KH : Decision making regarding Smith-Petersen vs. pedicle subtraction osteotomy vs. vertebral column resection for spinal deformity. Spine (Phila Pa 1976) 31(19 Suppl) : S171-S178, 2006

5. Bridwell KH, Lewis SJ, Lenke LG, Baldus C, Blanke K : Pedicle subtraction osteotomy for the treatment of fixed sagittal imbalance. J Bone Joint Surg Am 85-A : 454-463, 2003

6. Buchowski JM, Bridwell KH, Lenke LG, Kuhns CA, Lehman RA Jr, Kim YJ, et al. : Neurologic complications of lumbar pedicle subtraction osteotomy: a 10-year assessment. Spine (Phila Pa 1976) 32 : 2245-2252, 2007

7. Choi HY, Hyun SJ, Kim KJ, Jahng TA, Kim HJ : Effectiveness and safety of tranexamic acid in spinal deformity surgery. J Korean Neurosurg Soc $60: 75-81,2017$

8. Choi HY, Hyun SJ, Kim KJ, Jahng TA, Kim HJ : Freehand S2 alar-iliac screw placement using K-wire and cannulated screw : technical case series. J Korean Neurosurg Soc 61 : 75-80, 2018

9. Choi HY, Hyun SJ, Kim KJ, Jahng TA, Kim HJ : Surgical and radiographic outcomes after pedicle subtraction osteotomy according to surgeon's experience. Spine (Phila Pa 1976) 42 : E795-E801, 2017

10. Daubs MD, Brodke DS, Annis $P$, Lawrence BD : Perioperative complications of pedicle subtraction osteotomy. Global spine J 6 : 630-635, 2016

11. Dickson DD, Lenke $L G$, Bridwell KH, Koester $L A$ : Risk factors for and assessment of symptomatic pseudarthrosis after lumbar pedicle subtraction osteotomy in adult spinal deformity. Spine (Phila Pa 1976) 39 : 1190-1195, 2014
12. Eskilsson K, Sharma D, Johansson C, Hedlund R : Pedicle subtraction osteotomy: a comprehensive analysis in 104 patients. Does the cause of deformity influence the outcome? J Neurosurg Spine 27 : 56-62, 2017

13. Glassman SD, Bridwell K, Dimar JR, Horton W, Berven S, Schwab F : The impact of positive sagittal balance in adult spinal deformity. Spine (Phila Pa 1976) 30 : 2024-2029, 2005

14. Gum JL, Carreon LY, Buchowski JM, Lenke LG, Glassman SD : Utilization trends of pedicle subtraction osteotomies compared to posterior spinal fusion for deformity: a national database analysis between 2008-2011. Scoliosis Spinal Disord 11 : 25, 2016

15. Gupta MC, Ferrero E, Mundis G, Smith JS, Shaffrey Cl, Schwab F, et al. : Pedicle subtraction osteotomy in the revision versus primary adult spinal deformity patient: is there a difference in correction and complications? Spine (Phila Pa 1976) 40 : E1169-E1175, 2015

16. Han S, Hyun SJ, Kim KJ, Jahng TA, Kim HJ, Lee BH, et al. : Multilevel posterior column osteotomies are not inferior for the correction of rigid adult spinal deformity compared with pedicle subtraction osteotomy. World Neurosurg $107:$ :839-845, 2017

17. Hyun SJ, Lee BH, Park JH, Kim KJ, Jahng TA, Kim HJ : Proximal junctional kyphosis and proximal junctional failure following adult spinal deformity surgery. Korean J Spine 14 : 126-132, 2017

18. Hyun SJ, Lenke LG, Kim YC, Koester LA, Blanke KM : Comparison of standard 2-rod constructs to multiple-rod constructs for fixation across 3-column spinal osteotomies. Spine (Phila Pa 1976) 39 : 1899-1904, 2014

19. Hyun SJ, Rhim SC : Clinical outcomes and complications after pedicle subtraction osteotomy for fixed sagittal imbalance patients : a long-term follow-up data. J Korean Neurosurg Soc 47 : 95-101, 2010

20. Kim HJ, Boachie-Adjei O, Shaffrey Cl, Schwab F, Lafage V, Bess S, et al. : Upper thoracic versus lower thoracic upper instrumented vertebrae endpoints have similar outcomes and complications in adult scoliosis. Spine (Phila Pa 1976) 39 : E795-E799, 2014

21. Kim HJ, lyer S : Proximal junctional kyphosis. J Am Acad Orthop Surg $24:$ 318-326, 2016

22. Kim JS, Kim SM : Surgical outcomes of post-fusion lumbar flatback deformity with sagittal imbalance. J Korean Neurosurg Soc 59 : 615621, 2016

23. Kim YJ, Bridwell KH, Lenke $L G$, Cheh $G$, Baldus $C$ : Results of lumbar pedicle subtraction osteotomies for fixed sagittal imbalance: a minimum 5-year follow-up study. Spine (Phila Pa 1976) 32 : 2189-2197, 2007

24. Kim YJ, Bridwell KH, Lenke LG, Glattes CR, Rhim S, Cheh G : Proximal junctional kyphosis in adult spinal deformity after segmental posterior spinal instrumentation and fusion: minimum five-year follow-up. Spine (Phila Pa 1976) 33 : 2179-2184, 2008

25. Makhni MC, Shillingford JN, Laratta JL, Hyun SJ, Kim YJ : Restoration of sagittal balance in spinal deformity surgery. J Korean Neurosurg Soc 61 : 167-179, 2018

26. Moon JW, Shinn JK, Ryu D, Oh SY, Shim YS, Yoon SH : Pelvic incidence can be changed not only by age and sex, but also by posture used during imaging. Korean J Spine 14 : 77-83, 2017 
27. Ohrt-Nissen S, Dahl B, Gehrchen $\mathrm{M}$ : Choice of rods in surgical treatment of adolescent idiopathic scoliosis: what are the clinical implications of biomechanical properties? - a review of the literature. Neurospine 15 : 123-130, 2018

28. Popa I, Oprea M, Andrei D, Mercedesz P, Mardare M, Poenaru DV : Utility of the pedicle subtraction osteotomy for the correction of sagittal spine imbalance. Int Orthop 40 : 1219-1225, 2016

29. Scheer JK, Lafage V, Smith JS, Deviren V, Hostin R, McCarthy IM, et al. : Maintenance of radiographic correction at 2 years following lumbar pedicle subtraction osteotomy is superior with upper thoracic compared with thoracolumbar junction upper instrumented vertebra. Eur Spine J 24 Suppl 1 : S121-S130, 2015

30. Smith JS, Shaffrey Cl, Klineberg E, Lafage V, Schwab F, Lafage R, et al. :
Complication rates associated with 3-column osteotomy in 82 adult spinal deformity patients: retrospective review of a prospectively collected multicenter consecutive series with 2-year follow-up. J Neurosurg Spine 27 : 444-457, 2017

31. Wang MY, Berven SH : Lumbar pedicle subtraction osteotomy. Neurosurgery 60(2 Suppl 1) : ONS140-ONS146; discussion ONS146, 2007

32. Yagi $M$, King $A B$, Boachie-Adjei $O$ : Incidence, risk factors, and natural course of proximal junctional kyphosis: surgical outcomes review of adult idiopathic scoliosis. Minimum 5 years of follow-up. Spine (Phila Pa 1976) 37 : 1479-1489, 2012

33. Yang BP, Ondra SL, Chen LA, Jung HS, Koski TR, Salehi SA : Clinical and radiographic outcomes of thoracic and lumbar pedicle subtraction osteotomy for fixed sagittal imbalance. J Neurosurg Spine 5 : 9-17, 2006 